\title{
El cuerpo y la mirada en la obra de Chen Chieh-jen
}

\author{
Susana SANZ GimÉNEZ \\ Universidad Complutense de Madrid.
}

\begin{abstract}
RESUMEN
Chen Chieh-jen es un reconocido artista internacional de origen taiwanés cuya obra reflexiona, desde una perspectiva poscolonial, sobre las relaciones de poder entre el llamado "centro" y la "periferia". Centrándome en su obra Lingchi-Ecos de una fotografía histórica (2002), este artículo presentará algunas nuevas aportaciones sobre cómo el cuerpo es usado para representar la dramática historia contemporánea de Taiwán, su política y su sociedad. El cuerpo será empleado por el autor para destacar los nefastos efectos del colonialismo y la globalización en Taiwán. El autor asimila ambos procesos a una "tortura china", a una larga mutilación. Igualmente, este cuerpo mutilado le servirá para criticar los enfrentamientos entre el gobierno chino de la República Popular China y el taiwanés durante la segunda mitad del siglo XX. Finalmente, prestaremos especial atención al papel simbólico y artístico de la mirada en esta obra, siempre teñida de una fuerte crítica hacia el poder.
\end{abstract}

Palabras clave: cuerpo; mirada; lingchi; colonización; globalización.

\section{The body and the look in the Chen Chieh-jen's work}

\begin{abstract}
Chen Chieh-jen is a Taiwanese video artist whose work shows the power relations between the so-called "mainstream" and "the periphery" from a postcolonial point of view. By focusing on one of his video artworks called Lingchi-Echoes of a Historical Photograph (2002), the article will demonstrate how the body is used as a metaphor in order to represent contemporary Taiwanese history, politics and society. Most notably, the body is used by the author to emphasize the effects of colonialism and globalization in Taiwan. Chen compares both as an everlasting process of mutilation and "Chinese punishment". This fragmented body will be use to critize the political struggles between the Chinese government (People's Republic of China) and Taiwanese politicians in the XXth century. Finally, special relevance will be given to the artistic and symbolic role of the gaze in this work, as a critic to the mainstream power.
\end{abstract}

Keywords: body; gaze; lingchi; colonialism; globalization.

"Sobre el cuerpo, se encuentra el estigma de los sucesos pasados, de él nacen los deseos, los desfallecimientos y los errores; en él se entrelazan y de pronto se expresan, pero también en él se desatan, entran en lucha, se borran unos a otros y continúan su inagotable conflicto [...] La genealogía, como el análisis de la procedencia, se encuentra por tanto en la articulación del cuerpo y de la historia. Debe mostrar al cuerpo impregnado de historia, y a la historia como destructor del cuerpo.”*

(Michel Foucault)

* FOUCAULT, Michel, "Nietzsche, la genealogía, la historia", en TERAN, Óscar (presentación y selección), El discurso del poder, México, Folios, 1983, p. 142. 


\section{Cuestiones preliminares a la creación de Lingchi-Ecos de una fotografía histórica.}

El punto de partida de la obra del artista taiwanés Chen Chieh-jen ${ }^{1}$ (n. 1960) es el estudio y el análisis de la representación del cuerpo, entendido éste como un receptáculo de los avatares históricos, de las idas y venidas del poder. Para investigar los estigmas dejados por el paso del tiempo en el cuerpo, Chen se servirá de la mutilación como fórmula estética que repetirá a lo largo de su obra como fotógrafo, performer y videoartista. De esta forma, la mutilación es empleada como una estrategia de representación del cuerpo a modo de metáfora de la historia de violencia y colonialismo a la que la isla de Taiwán se ha visto sometida durante siglos. Por lo tanto, la obra de Chen y el arte de Taiwán en general, no pueden explicarse sin conocer el devenir histórico de Formosa en los últimos cien años. Un pasado vinculado irremediablemente a los continuos procesos de colonización, como es el caso de la presencia extranjera de españoles, portugueses y holandeses o del imperio japonés en la isla (1895 y 1945) y a las casi cuatro décadas de dictadura del general Chiang Kai-shek (1887-1975), un periodo denominado como ley marcial (1949-1987).

La mutilación no sólo será interpretada como símbolo de aquellos rastros dejados en forma de heridas por la historia oficial en el cuerpo de la sociedad, en su propio cuerpo, sino también para sacar a la luz aquellos miembros que precisamente habían sido amputados, que estaban ausentes y que representan el vacío, lo olvidado. Como por ejemplo las recientes reivindicaciones de la identidad taiwanesa reprimida por el poder del gobierno del Kuomintang (KMT). En la obra de Chen siempre hay una ausencia, una sombra, algo perdido, pero cuyo vacío es tan poderoso que termina por convertirse en perturbadora corporeidad.

Todos estos aspectos artísticos de Chen podemos apreciarlos en su primera obra de videoarte, cuyo proceso de creación comienza cuando en el año 1995 un amigo del artista le regaló el libro Las lágrimas de Eros (Les Larmes d'Éros, 1961)² del escritor y pensador francés Georges Bataille (1897-1962). Aunque Chen no podía leerlo porque estaba escrito en inglés, observó con detenimiento la impresionante fotografía de la víctima de lingchi o del "castigo de los mil cortes" al que el libro se refería. Castigo también conocido popularmente como "tortura china", que tanto obsesionó al intelectual francés y que tampoco dejaría indiferente a Chen. Tanto es así, que esta horripilante imagen de principios del siglo XX no sólo formaría parte de su primera serie en blanco y negro a través de su recreación Genealogía de si

\footnotetext{
1 A lo largo del texto, el lector encontrará las palabras y nombres de la lengua china transcritas según el sistema conocido como Wade-Giles en lugar del pinyin. La elección de uno en lugar del otro se debe simplemente a respetar el sistema con el que el artista taiwanés Chen Chieh-jen transcribe su propio nombre.

2 Hay que mencionar que existen grandes dudas acerca de la autoría de la obra atribuida a Bataille, al encontrarse éste muy enfermo en el momento de la publicación del libro. Para más detalles leer la introducción a la obra realizada por LO DUCA, Joseph-Marie, "Georges Bataille, au loin...", en BATAILLE, Georges, Les Larmes d'Eros, Paris, Éditions 10/18, 1961, pp. 9-23.
} 
mismo, 1905-1996 (1996), sino que imprimir vida y movimiento a esa fotografía le conduciría a su debut en el mundo del videoarte con la obra Lingchi-Ecos de una fotografía histórica (2002). (fig.1) (fig.2)

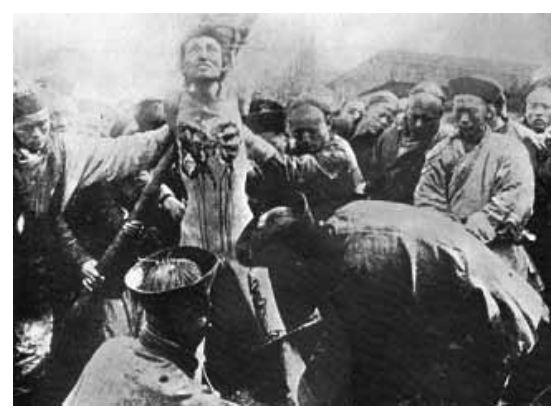

Fig. 1. Autor anónimo, Ejecución por lingchi de pseudo Fu Zhuli, fecha desconocida, fotografía en blanco y negro.

Incluso el mismo concepto chino lingchi que da título a la obra que nos ocupa refuerza esa ya mencionada querencia por lo inacabado, lo fragmentado e incompleto en la obra del taiwanés. Puesto que este término, lingchi, serviría para referirse al largo y lento castigo público por desmembración que se popularizó en la Europa de principios del siglo XX, sin duda mediante los testimonios de los soldados y viajeros europeos que presenciaron o tomaron fotografías de tal cruento suplicio en China. De modo que la difusión de estas imá-

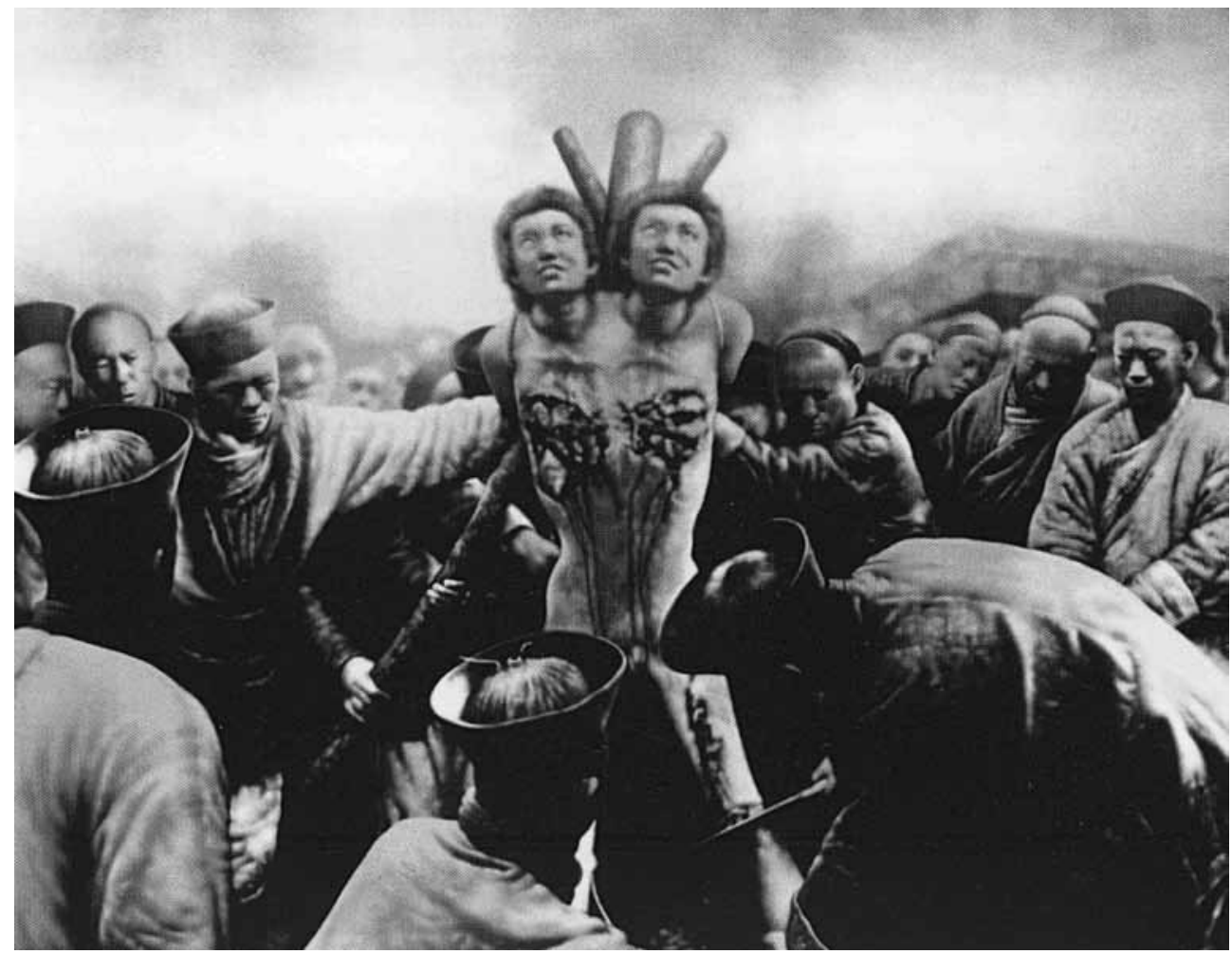

Fig. 2. Chen Chieh-jen, Genealogía de si mismo, 1996, fotografía digital en blanco y negro, 208 x $260 \mathrm{~cm}$, Colección Chi-wen Gallery. 
genes en libros y a través de postales jugó un papel clave en la interpretación que Occidente realizara de China y por extensión de ese otro constructo denominado Oriente $^{3}$. Sin embargo, tal y como indica el investigador francés Jérôme Bourgon, el concepto lingchi sólo aparece tipificado como delito en el código penal tardíamente. No será hasta comienzos de la dinastía Liao (907-1125), hacia el año 920 cuando este castigo aparezca mencionado en las fuentes de la Historia de la dinastía Liao ${ }^{4}$. Pese a ello, en Occidente a principios del siglo XX era considerado como la forma más típica de castigo del sistema penal chino. Sabemos que la penalidad china tiene una larga tradición vinculada al castigo corporal a través de la pena por desmembración que se conocía generalmente como zhe. Sin embargo, éste y otros términos referidos a castigos físicos no deben confundirse con este otro de lingchi y su práctica concreta a finales del periodo Qing (1644-1911), de la que los europeos tuvieron conocimiento. Igualmente es importante destacar que si bien los occidentales se aferraban a estas imágenes sádicas para conformar su visión peyorativa de China, olvidaban contradictoriamente que hasta 1814 habían existido castigos similares, como por ejemplo el descuartizamiento (quartening) en países como Inglaterra. En contra de la creencia europea los testimonios de intelectuales, hombres de leyes y políticos chinos demuestran que los propios chinos consideraban el lingchi como el más extremo de entre todos los llamados "castigos extremos", lo que sin duda finalmente llevó a proponer su abolición por el estudioso y jurista Shen Jia-ben (1849-1913) en 1905. Aunque su eliminación se produjera a principios del siglo XX, la lengua china moderna ha recuperado el uso del término lingchi para designar aquellos trabajos repetitivos e inhumanos, así como para describir las condiciones laborales consideradas lamentables ${ }^{5}$.

Este modo de ejecución consistía en la desmembración, la fragmentación de los huesos y la dislocación de las partes del cuerpo de los criminales siguiendo unas pautas y un orden que podrían calificar el acto de ritualizado. Desde su inclusión en el código penal en la dinastía Yuan (1279-1368) hasta su abolición en abril de 1905, el lingchi era un castigo destinado a los acusados juzgados por tres tipos de crímenes: el familiar, el considerado atroz e inhumano por la moral china y el de lesa majestad, es decir el que atentaba contra el emperador o suponía una rebelión y ofensa contra la dignidad del sistema imperial chino. Como sucediera en el caso de Fu Zhuli (1880-1905), un guardia al servicio de un príncipe mongol al que asesinó en febrero de 1905 y por lo que fue condenado a morir desmembrado públicamente en Beijing en abril de aquel mismo año. La escena fue contemplada

3 GARCIA CANCLINI, Néstor, Diferentes, desiguales y desconectados. Mapas de la interculturalidad, Barcelona, Gedisa, 2004, p. 213.

4 Para más información sobre la historia de lingchi consultar: BOURGON, Jérôme: "Lingchi. Brève histoire d'un trop fameux supplice chinois.", en http://turandot.ish-lyon.cnrs.fr/Essay.php?ID=22 (última consulta 16 de agosto 2010).

5 CHEN, Chieh- jen, Statement: Lingchi-Echoes of a Historical Photograph, 2002. 
por un gran número de personas que acudieron como público, algunos asistentes europeos tomaron fotografías que terminarían por ser publicadas como una serie de doce postales que se comercializaron para su uso en Europa. El destino de este acusado junto con las fotografías de otras víctimas de lingchi pasarían a ser tema de no pocos artículos y libros publicados en Europa desde 1905 y sin lugar a dudas dirigidos a un público europeo.

La descripción del castigo público y de algunas de esas fotografías las encontramos en el artículo del explorador francés Philippe Berthelot (1866-1934) titulado Los suplicios en China (Les supplices en Chine, 1905). Hay que hacer notar que Berthelot no informa sobre el nombre de la víctima de lingchi acaecido en Beijing, en su artículo tampoco se muestran las fotografías que le inspiraron y que dice, un occidental inmortalizó ${ }^{6}$. Sin embargo, con la misma fecha de publicación que este artículo, Jean-Jacques Matignon, ex-agregado de la Delegación Francesa en Beijing en el momento de la publicación del artículo, escribe sobre el mismo asunto y ofrece una serie de fotografías facilitadas por un amigo suyo, un soldado que tomó las imágenes del castigo de un mongol que asesinó a uno de sus príncipes ${ }^{7}$. Existen por tanto detalles coincidentes entre ambos relatos para poder pensar que la muerte que describen tanto Berthelot como Matignon fuera la de Fu Zhuli, uno de los últimos criminales sentenciados a lingchi en China. Sin embargo ninguno de los dos autores ofrece el nombre de la víctima, lo cual dificulta dar una conclusión rigurosa al respecto de la identidad del supliciado.

El viajero y escritor francés Louis Carpeaux (1873-1920?), autor del libro El Pekín que desaparece (Pékin qui s'en va, 1913), mencionó este mismo suceso en su libro y recogió las mismas imágenes que Matignon. Pese a no estar presente en el momento del cruel desmembramiento de Fu Zhuli, describe con detalle la expresión del rostro de torturado. Desde el encrespamiento de su cabello por el dolor hasta la apertura de su boca previamente a recibir el golpe mortal del verdugo $^{8}$. Sin embargo, en su libro no eran incluidas las mismas imágenes de lingchi que años más tarde el profesor de la Universidad de la Sorbona (París) Georges Dumas (1866-1946) recogería en su Tratado de Psicología (Traité de psychologie, 1923) y a través del cual Georges Bataille accedió a ese cliché fotográfico. Por lo tanto podemos afirmar que las series fotográficas de lingchi usadas por Matignon y Carpeaux en sus libros son las mismas, mientras que las empleadas por Dumas y, a través de él, Bataille son otras diferentes. En conclusión la identidad de la víctima de lingchi en cada uno de estas dos series de imágenes es también distinta. La transmisión del conocimiento del lingchi a través de esas series fotográficas ex-

6 BERTHELOT, Philippe, “Les supplices en Chine”, en Je sais tout, encyclopédie mondiale illustrée, 15 de octubre de 1905, pp. 289-296.

7 MATIGNON, Jean-Jacques, “Un supplice qui disparaît en Chine: Le Lynchii”, en Archives d'anthropologie criminelle, de criminologie, de psychologie normale et pathologique, $\mathrm{n}^{\circ} 142,15$ de octubre de 1905, pp. 834-841.

8 CARPEAUX, Louis, Pékin qui s'en va, Paris, Maloine, 1913, p. 186. 
plica cómo este castigo terminó por adquirir gran popularidad en la configuración de la visión de China en Europa. Pero al mismo tiempo la historia de su difusión designa la carencia de rigor a la hora de contrastar las fuentes documentales con las visuales, como podemos observar simplemente al hojear el libro de Bataille Las lágrimas de Eros y las imágenes del libro de Carpeaux al que cualquier investigador puede acceder en la Biblioteca Nacional de Francia en París. Hoy en día sabemos que Bataille leyó estas obras de principios del siglo XX de un modo poco riguroso, puesto que no dudó en usar el texto de Carpeaux para describir el proceso de lingchi, al tiempo que incluía una fotografía que él identificó como el castigo a Fu Zhuli pero que pertenecía a otro criminal castigado del mismo modo y que aparecía en la obra de Dumas. Por lo tanto, la célebre fotografía usada por Bataille no puede ser confundida con la del denominado Fu Zhuli que aparece en los libros de Matignon y Carpeaux, así como en diferentes series de fotografías y de postales de principios de siglo XX.

Recientemente, el investigador francés Jérôme Bourgon y su proyecto realizado entre los años 2003 y 2005 en L'Institut d'Asie Orientale (IAO) de Lyon (Francia) ${ }^{9}$ han compilado un gran número de imágenes fotográficas, álbumes de viajes, postales, textos y en definitiva todo tipo de testimonios de los colonizadores occidentales en Asia, que constituyen un archivo digital centrado en la visión del otro construida a partir del fenómeno de la "tortura china". El objetivo de Bourgon no radicaba tanto en analizar al oriental como objeto de estudio, sino en estudiar el fenómeno mismo del orientalismo como disciplina que ofrece información sobre la forma de mirar de nuestros doctos y eruditos antepasados colonizadores. El grupo trabajó desde una perspectiva compleja por ser completa, rigurosa, abarcando diversos campos y sin duda, al abrigo de los estudios poscoloniales. En este sentido, una de las líneas de investigación abrazada por el grupo francés ha sido el origen de la fotografía que nos ocupa, con el fin de arrojar luz sobre la autoría de la misma y sobre la identidad del personaje mutilado.

La investigación de Bourgon juega un papel clave para comprender el proceso de documentación previo a la filmación del primer video de Chen, puesto que en el año 2000 tuvo un encuentro decisivo con el investigador francés que le ofreció mucha información sobre el suplicio chino, desde una aproximación más completa que la que realizara Bataille y el resto de escritores mencionados ${ }^{10}$.

La elección de Chen para trabajar sobre este tema estuvo motivada porque dicha fotografía, que sólo será mostrada al final de este video, era un buen ejemplo de cómo la identidad del colonizado había sido prefigurada por otros a través de los procesos continuos de colonialismo que no habían hecho más que incidir en la

9 http://turandot.ish-lyon.cnrs.fr (última consulta 16 de agosto 2010).

${ }^{10}$ Entrevista de Susana Sanz a Chen Chieh-jen, Estudio del artista en Taipei (Taiwán), 6 de noviembre de 2007, 13-16 pm. 
desmembración de China como estado-nación, y en la separación de Taiwán del continente. Por lo tanto, esta imagen le sirvió al artista para retroceder en el tiempo, hasta los orígenes mismos de la fragmentación y del sometimiento de la historia de China y Taiwán a un proceso de lingchi:

"Él comenzó a examinar la condición fragmentaria desde la perspectiva del destino de China y descubrió que este estado dividido de China/Taiwán estaba originado en el colonialismo. Los tratados desiguales impuestos sobre China por los poderes imperiales causaron la separación del estado-nación chino y las fronteras nacionales. El Tratado de Shimonoseki (bajo el cual Taiwán y [las Islas] Pescadores fueron cedidas a Japón por el gobierno manchú en 1895) provocó que Taiwán fuera separada de China. Sobreviviendo en este estado colonial, la población china/taiwanesa comenzó a fantasear sobre la modernidad, causando una separación entre ellos y su cultura tradicional."11

La ausencia corporal a la que remite la mutilación por lingchi no hace más que indagar nuevamente en la cuestión del desarrollo de la identidad taiwanesa a lo largo de los años posteriores a la ley marcial. Siguiendo la interpretación de la comisaria de arte taiwanés Amy Cheng, podríamos afirmar que la situación política de Taiwán como estado de facto pero no de jure puede representarse como la imagen de un cuerpo que podríamos tocar, que tiene presencia física pero que al mismo tiempo es un cuerpo incompleto como el del castigado a sufrir el lingchi. El casi inexistente reconocimiento internacional de Taiwán como país no hace más que aumentar esa sensación de pérdida del cuerpo, de presencia fantasmal. Además, el vacío existente, es decir el desconocimiento que existía sobre dicha imagen en China y Taiwán es lo que le interesó a Chen a la hora de reinterpretar la imagen. Puesto que es un artista cuya obra se mueve en el territorio de las cosas perdidas y olvidadas. Es por ello que mientras aquellos intelectuales reflexionaban una y otra vez sobre la terrible escena de la fotografía que obsesionó a Bataille, Chen se recreará en filmar el rostro del anónimo fotógrafo de la imagen, las efigies pétreas e inexpresivas del público asistente a la tortura descrita por Carpeaux ${ }^{12}$. Para de este modo ilustrar las relaciones entre el considerado centro y la supuesta periferia a lo largo del proceso de construcción de la historia ortodoxa, cuyo discurso excluye los relatos escritos en los bordes. Por ello y pese a su reinterpretación de la fotografía, la aportación de su lectura siempre será menospreciada o dejada de lado frente a la ofrecida por la mirada errónea de Bataille ${ }^{13}$.

11 PAN, An-yi, "Contemporary Taiwanese Art in the Era of Contention”, en PAN, An-yi (ed.), Contemporary Taiwanese Art in the Era of Contention, catálogo de la exposición (Taipei, 3 de abril -15 de agosto de 2004), Taipei, Taipei Fine Arts Museum Publishing, 2004, p. 156.

12 CARPEAUX, Louis (1913), op. cit., p. 73.

13 Entrevista de Susana Sanz a Chen Chieh-jen, Toledo (España), 13 de octubre de 2008, 17-18 horas. 


\section{Mirar a través de las heridas: un análisis de la representación del cuerpo y la mirada en relación con el colonialismo.}

Si pasamos a analizar algunas de las escenas clave del video siguiendo su orden de aparición, nos damos cuenta de cómo el suceso histórico de la práctica penal no es filmado con una voluntad documental ni realista por parte de Chen. Prueba de ello son los anacronismos confesados en los que el artista incurre intencionadamente a través de los siete y no ocho cuchillos del "castigo de los ocho cuchillos" con los que se ejecutaba el lingchi a finales de Qing; la vestimenta y los diferentes cortes de pelo que combinan la tonsura manchú del público asistente y la víctima, con las ropas modernas de los trabajadores taiwaneses ${ }^{14}$. Porque por encima de todo Chen es un artista al que le interesa filmar aquello que nunca nos es mostrado, lo que es sistemáticamente eliminado porque no corresponde a lo que la forma de ver oficial (en este caso la mirada del colonizador) quiere presentar. Por eso Chen se detiene en los preparativos, en los preliminares del castigo ${ }^{15}$, en el proceso de ejecución, en los allí presentes; pero concede una menor importancia al resultado, es decir a la famosa fotografía. Además, a través de la técnica de ralentización de la imagen (slow-motion) y de la proyección fragmentada y no sincronizada de la obra en tres canales, Chen no sólo recrea ese proceso lento y duradero de la mutilación ${ }^{16}$, sino que también permite la observación pormenorizada de la que nos había privado la tecnología fotográfica. Así, el propio espectador del video se ve sometido a una especie de estupefacción que una vez más la hace partícipe del hecho histórica, de este simulacro teatral del horror. Al mismo tiempo, la ralentización de la imagen en este video como en obras posteriores de Chen, se convierte en una especie de marca personal, de factura de la pincelada creadora que no hace más que permitir al espectador concentrarse en una visión escrutadora, intensiva y analítica ${ }^{17}$.

La cámara no cesa de moverse rodeando la escena de la tortura con un travelling continuo adentrándose en las sangrantes heridas del pecho, filmando sin tapujos un primerísimo plano del rostro del doliente que resulta obsceno y pornográfico como calificara Jean Baudrillard a los primeros planos ${ }^{18}$. Así, el artista consigue que el espectador penetre en la historia desde una perspectiva múltiple: la de los espectadores del cruel acto, la del verdugo, al mismo tiempo que la de la víctima y la del occidental que supuestamente tomó la fotografía; una oportunidad a la que la fotografía original no nos había abierto las puertas. De este modo Chen parece

14 CHEN, Chieh-jen (2002), op. cit.

15 MICHEL, Régis, L'oeil-écran ou la nouvelle image. 100 vidéos pour repenser le monde, catálogo de la exposición (Luxemburgo, 24 de marzo-17 de junio 2007), Luxembugo, Casino Luxembourg-Forum d'art contemporain, 2007, p. 305.

16 LIN, Chi-Ming, "Mémoire, histoire, généalogie", en Asiatica II. Chen Chieh-jen, catálogo de exposición, (París, 20 de febrero-20 de mayo de 2001), París, Galerie Nationale du Jeu de Paume, p. 10.

17 MICHEL, Régis (2007), op. cit., p. 306.

18 BAUDRILLARD, Jean, El otro por sí mismo, Barcelona, Anagrama, 1994, p. 37. 
querer retomar las palabras de Michel Foucault cuando éste hace alusión a cómo el castigo público en las culturas pre-modernas tiene la capacidad de que, en el último momento los papeles de los protagonistas puedan tornarse: el verdugo se convierte en el criminal y los jueces en los asesinos de aquél que sufre el suplicio, objeto de piedad y admiración al mismo tiempo ${ }^{19}$. El artista taiwanés quiere revivir ese preciso momento en el que las jerarquías parecen verse quebrantadas e invierten sus papeles, para reforzar la visibilidad de lo invisible que empuja la creación de su obra.

Para Chen, las miradas del público chino asistente a la ejecución en el momento de ser tomada la fotografía, así como nuestra propia mirada como espectadores externos, generan un juego especular de miradas entre unos y otros. Sin embargo, y aplicando la interpretación de lo posmoderno por Michel Hardt (n. 1960) y Antonio Negri (n. 1933) ${ }^{20}$ al análisis de la mirada en esta obra, este cruce de miradas no se produce únicamente entre el interior y el exterior, el adentro y el afuera, el centro y la periferia, si se prefiere. También a lo largo del proceso de mutilación, la mirada adquiere una dimensión múltiple. Nosotros observamos pero el verdugo, el público y el mismo torturado también parecen devolvernos la mirada. A través de la intervención de unos ojos cuyas pupilas reflejan la ejecución, el espectador se convierte en receptor del dolor del cuerpo de la víctima.

En ese intento por dar visibilidad a los detalles ocultos de la fotografía, el artista posa su finísima lente sobre otros aspectos relacionados con el cuerpo y la mirada como un paquete de opio, con una balanza dibujada en representación de una justicia más que dudosa, la que creía representar Occidente y en el que pueden leerse las palabras: Compañía de las Indias Orientales (East India Company). El opio le es suministrado al torturado para que sea capaz de soportar la penosa mutilación de su cuerpo durante más tiempo o como diría Matignon para producir una obnubilación de su sensibilidad $^{21}$, (fig. 3). Pero este frame del video no es un detalle casual de mera rigurosidad histórica sino más bien una crítica a la razón de ser comercial del colonialismo, a la forzosa narcotización de la población china que impulsó las coloniales guerras del opio en el siglo XIX. A causa de la droga, la víctima, trasunto de China misma, entra en un

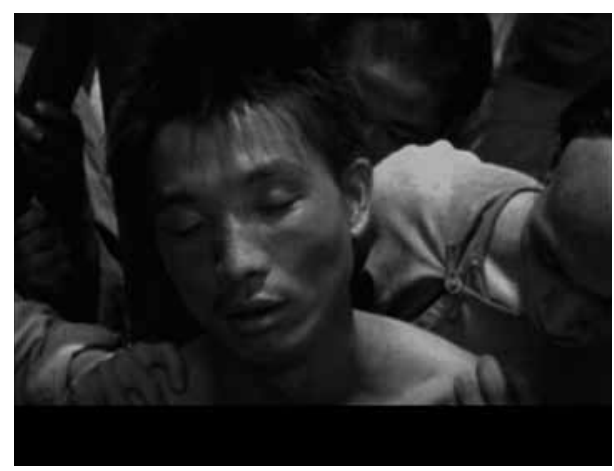

Fig. 3. Chen Chieh-jen, Lingchi-Ecos de una fotografía histórica, 2002, película de $16 \mathrm{~mm}$. transferido a DVD, blanco y negro, sonido, proyección en triple canal, 21'04'".

\footnotetext{
19 FOUCAULT, Michel, Surveiller et punir. Naissance de la prison, París, Gallimard, 1975, p. 15.

20 HARDT, Michael, NEGRI, Antonio, Imperio, Barcelona, Paidós, 2002, pp. 136-137.

21 MATIGNON, Jean-Jacques (1905), op. cit, p. 836.
} 
estado de estupefacción que moldea su rostro con una oscilante mueca, mezcla de sufrimiento y sonrisa sutil. El artículo de Berthelot estableció la creencia común de que las víctimas del lingchi paradójicamente sentían "el goce del éxtasis"22, una apreciación que influyó en varios autores. Entre ellos Dumas que, de un modo prudente, intentará analizar este fenómeno recogido en las fotografías de víctimas de lingchi, siempre a través de un acercamiento científico. Por lo tanto, para el académico francés esta expresión del doliente sonriendo en el momento de sufrir no deja de ser perturbadora y terminará por considerarla como un fenómeno fuera de la norma de las reacciones musculares ${ }^{23}$. Bataille también se haría eco de esta imagen para elaborar su teoría sobre el momento concreto en el que la muerte y el erotismo parecen encontrarse en el rostro extático del supliciado ${ }^{24}$. Chen reproduce la imagen sugiriendo el error interpretativo de Bataille, causado por la visión propia del colonizador que se enfrenta a la imagen del colonizado como si se tratara de un objeto lleno de exotismo, que le permite fantasear ${ }^{25}$.

La verdadera novedad introducida por el artista en relación con el tratamiento de la fotografía histórica y la mirada radica en mostrar el rostro del fotógrafo occidental que presuntamente captó la imagen. (fig. 4) Y lo hará a través de las heridas del cuerpo de la víctima, como si fuera una confirmación visual de esa relación entre cuerpo y mirada. Pero también como metáfora de una China herida y expoliada por los ataques del colonialismo, el cual ha configurado la forma de ver y de verse a si mismos en la construcción de su identidad. Como el artista redirecciona la visión, el objeto de contemplación que satisface la curiosidad exótica colonizadora ya no es el llamado bárbaro. Es más, el que era considerado el otro es el que pasa a controlar la mirada, objetualizando al que tradicionalmente se creía en su derecho de observar; cumpliéndose así las peores pesadillas del colono:

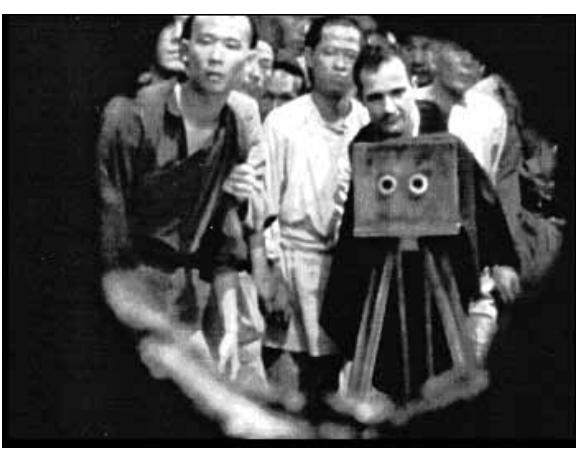

Fig. 4. Chen Chieh-jen, Lingchi-Ecos de una fotografía histórica, 2002, película de $16 \mathrm{~mm}$. transferido a DVD, blanco y negro, sonido, proyección en triple canal, 21'04”.

“[...] en el intercambio de miradas entre nativo y colono que estructura su relación psíquica en la fantasía paranoide de la posesión sin límites y su conocido lenguaje de inversión: 'Cuando sus miradas se encuentran [el colono] afirma amargamente, siempre a la defensiva: 'Quieren tomar nuestro lugar'. Es cierto, pues no hay nativo que no sueñe

22 BERTHELOT, Philippe (1905), op. cit., p. 290.

23 DUMAS, Georges, Nouveau traité de psychologie, vol. II, París, Alcan, 1932, p. 286.

24 BATAILLE, Georges (1961), op. cit., pp. 120-122.

25 BHABHA, Homi. K., El lugar de la cultura, Buenos Aires, Manantial, 2002, pp. 101-102. 
al menos una vez al día con ponerse en el lugar del colono'. El deseo colonial siempre se articula en relación con el lugar del Otro: el espacio fantasmático de la posesión que ningún sujeto puede ocupar singularmente o con fijeza, y en consecuencia permite el sueño de la inversión de papeles."26

Como indica Amy Cheng la estructura de este video es muy compleja en lo referente a la mirada, puesto que reflexiona sobre qué es ser exótico y más importante aún, quién decide esa condición de exotismo. Al conectar nuestra mirada con aquellas otras proyectadas desde el interior de la obra se genera un espacio de conexión entre el adentro y el afuera de la imagen, entre quién es víctima, quién es público. Y por encima de todo, Chen nos hace repensar sobre cómo se ven los occidentales y los orientales entre si y sobre quién es para quién el objeto de exotismo en esa relación dual ${ }^{27}$. En ese encuentro de ambas miradas que se produce en esa escena del video surge la anulación del poder del uno sobre el otro, la mirada del que se creía el fuerte ya no puede ejercer su poder porque todo lo que es mirado vuelve su mirada a los ojos que lo miran, que no se dejan convertir en objeto silencioso sino que más bien interrogan al que le observa:

"Descubrir unos ojos que también nos miran es asistir, de forma repentina, a la emergencia, en el campo de lo visible, de unas formas que no se dejan tematizar, que se resisten a la posesión representativa: los ojos que nos miran abren un espacio más allá -o más acá- del ser de lo visible, en la medida que instauran un espacio, el espacio del encuentro, en el que la mirada ya no puede ejercer su poder." 28

\section{Conclusiones}

Esta fotografía que inspiró el trabajo de Chen Chieh-jen era una de aquellas muchas imágenes de "tortura china" que circulaban a modo de postales por Europa a finales del siglo XIX y comienzos XX. Esas postales no sólo son fragmentos escogidos para demostrar y argumentar la narración que Occidente quería escuchar sobre el otro, sino también para hacer valer el privilegio del que creía gozar el colonizador occidental: "[...] porque la suya era la cultura más fuerte; él podía penetrar, abarcar, dar forma y significado al gran misterio asiático, como Disraeli lo expresó una vez." ${ }^{29}$

Estas postales que se convirtieron en la forma más efectiva de enviar imágenes sobre países considerados exóticos, terminaron por desarrollar una floreciente industria independiente creada por y para el mercado internacional. Sólo tardíamente

${ }^{26}$ Ibid., p. 65.

${ }^{27}$ Entrevista de Susana Sanz a Amy Cheng, 2007.

${ }_{28}$ ANTICH, Xavier, "Ver para mirar. De la imagen-control a la imagen-deseo", en FERNANDEZ POLANCO, Aurora (ed.), Cuerpo y mirada, huellas del siglo XX, Madrid, Museo Nacional Centro de Arte Reina Sofía, 2007, p. 97.

${ }^{29}$ SAID, Edward, Orientalismo, Barcelona, De Bolsillo, 2008, p. 73. 
y coincidiendo con la caída del sistema imperial en 1911 podemos testimoniar un interés propiamente chino por fotografiarse tal y como China se veía a si misma ${ }^{30}$. Además, a través del trabajo de fotógrafos como el escocés John Thomson (18371931) y sus imágenes de China también se pueden rastrear los estrechos lazos que unirían la historia de la fotografía con el proyecto colonialista y su sed de información sociológica ${ }^{31}$. Gracias a esta documentación visual podríamos afirmar que existe en el hombre una tendencia natural a lo horrendo en su encuentro con otras culturas, a las que terminamos por estigmatizar. Como diría Néstor García Canclini, reafirmando la extrañeza de la otredad y el rechazo de su diferencia al ir depositando en lo otro todo aquello que negamos en nosotros, precisamente protegemos nuestra imagen ${ }^{32}$. De ello daría buena muestra la historia de la imagen fotográfica vinculada al colonialismo. En esta historia de miradas colonizadas y de control, la fotografía jugó un papel clave para acercar pero también para alejar, para analizar lo que se suponía un problema y para justificar su resolución a través del sometimiento ${ }^{33}$.

Chen ilustra la condena del criminal y su consecuente suplicio como forma de demostrar el poder imperial ante cualquier intento de subversión, al mismo tiempo que otra táctica de poder está siendo llevada a cabo, la del colonizador que se sirve de la tecnología, esto es de la cámara fotográfica, para demostrar su superioridad cultural ante el salvajismo nativo. Estableciendo a su vez una jerarquía en las relaciones de poder a través de la forma de tomar la fotografía, en el ángulo que el fotógrafo utilizó destacando unos aspectos sobre otros. Los dos círculos perforados en el cuerpo del mutilado podrían ser vistos como dos ojos a través de los cuales el espectador puede ver aquello que nunca se le había permitido observar, puesto que el occidental que portaba la cámara ofrecía un sesgo muy marcado de la mirada, aportaba filtros a partir de los que mirar y representar al oriental.

Los orificios del cuerpo de la víctima de lingchi no sólo delatan el rostro del fotógrafo occidental, sino que también nos ofrecen una segunda imagen plena de simbolismo, la de dos trabajadoras taiwanesas (fig. 5) que flanquean al mutilado, ataviado con ropas actuales. Estas dos mujeres resultarán familiares para aquellos que conozcan la obra de Chen titulada La fábrica (2003). En este fotograma, Chen hace convivir el tiempo pasado, evocado por la víctima, con el momento contemporáneo representado por las trabajadoras. Además, la chaqueta que cubre el ajado cuerpo del mutilado de Lingchi es el producto que simboliza la industria floreciente manufacturera taiwanesa de los años sesenta. A causa de la deslocalización económica de los años noventa y su búsqueda por abaratar los costes de la producción, reclutando mano de obra barata entre la población de países como China; Taiwán

\footnotetext{
30 THIRIEZ, Régine, "Imperial China in Postcards”, en Orientations, junio 2004, p. 51.

31 ROSEMBLUM, Naomi, Une histoire mondiale de la photographie, Paris, Abbeville, 1996, p. 168.

32 GARCIA CANCLINI, Néstor (2004), op. cit., p. 213.

33 SAID, Edward (2008), op. cit., pp. 278-279.
} 


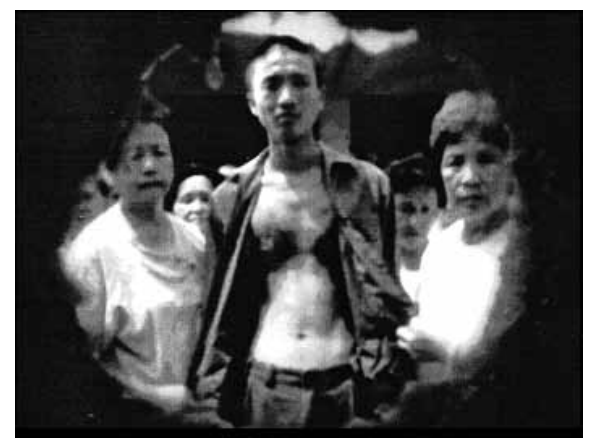

Fig. 5. Chen Chieh-jen, Lingchi-Ecos de una fotografía histórica, 2002, película de $16 \mathrm{~mm}$. transferido a DVD, blanco y negro, sonido, proyección en triple canal, 21'04'. nales que colaboraron en Lingchi como público asistente a la tortura eran trabajadores desempleados, vestidos al estilo de la dinastía Qing. Ellos son las víctimas del colonialismo y de la globalización, porque el fin del primero no dio paso a una era de libertad sin reservas, es más generó nuevas formas de dominio a escala mundial ${ }^{35}$. Así, el pasado y el presente se conectan a través de estos dos procesos internacionales que Chen considera heredero y consecuencia el uno del otro y que convierten el cuerpo de la población en un cuerpo inmóvil bajo la globalización, en una víctima de ese largo proceso de $\operatorname{ling} \mathrm{chi}^{36}$.

\footnotetext{
34 KLEIN, Naomi, No Logo. El poder de las marcas, Barcelona, Paidós, 2005, p. 270.

35 HARDT, Michael, NEGRI, Antonio (2002), op. cit., p. 132.

36 PAN, An-yi (2004), op. cit., p. 162.
} 